\title{
Clinical study on combining femtosecond thin- flap and LASIK with the Triple-A profile for high myopia correction
}

\author{
Kai Li ${ }^{*}{ }^{*}$, Chuan-Wei Zhang ${ }^{\dagger}$, De-Jian Hong ${ }^{\dagger}$, Jing Wu and Yi-Shuo Yao
}

\begin{abstract}
Background: Femtosecond laser-assisted LASIK (FS-LASIK) can make ultra-thin corneal flap accurately. MEL 90 excimer laser provides Triple-A ablation mode, which significantly reduces the amount of corneal tissue cutting. This study aimed to investigate the visual and refractive outcomes in patients with high myopia after thin-flap FSLASIK using the $500 \mathrm{~Hz}$ pulse rate of the Triple-A profile.
\end{abstract}

Methods: This prospective study included 90 eyes from 90 patients received thin-flap FS-LASIK using the $500 \mathrm{~Hz}$ pulse rate of the Triple-A profile. According to the pre-operative spherical equivalence (SE), the treated eyes were divided into two groups: the first group (ranged from $-9.0 \mathrm{D}$ to $-6.0 \mathrm{D}$ ) and the second group (ranged from $-11.15 \mathrm{D}$ to -9.0 D). The parameters evaluated pre-operatively and 6 month post-operatively included uncorrected distance visual acuity (UDVA), corrected distance visual acuity (CDVA), SE, efficacy and safety index, posterior central elevation, and corneal higher-order aberrations (HOAs).

Results: The efficacy indexes were $1.149 \pm 0.150$ for the first group and $1.173 \pm 0.136$ for the second group $(P>0.05)$, whereas safety indexes were $1.135 \pm 0.154$ and $1.158 \pm 0.137(P>0.05)$ respectively. Moreover, 93.8 and $90.6 \%$ of patients had an UDVA of 20/20, 51.2 and $49.8 \%$ had a UDVA of 20/16 for the first and second groups, respectively; yet, there were no significant differences between both groups at the $20 / 20$ and the 20/16 levels $(P>0.05) .84$ and 100\% of the firse group patients had a SE within $\pm 0.5 \mathrm{D}$ and $\pm 1.0 \mathrm{D}$, and 82 and $100 \%$ of the second group patients. There was no significant myopia regression in both groups after 6 months follow-up. At 1, 3 and 6-month after surgery, there were no significant differences in the posterior central elevation between the two groups $(P>0.05)$. The induction of total HOAs, spherical aberration, and horizontal coma in the first group were significantly less than that in the second group at the 6- month follow-up $(P<0.05)$, while the differences of the RMS value of vertical coma between both groups were not significant $(P>0.05)$. The ablation was significantly associated with the post-operative increase in total HOAs, spherical aberration and horizontal coma $(P<0.05)$,but not with vertical coma $(P>0.05)$.

Conclusion: Our results indicate that using the Triple-A ablation profile of the MEL 90 excimer laser associated with thin-flap is a safe, efficient, and predictable method to correct SE up to - 11.15D. However, for patients with high myopia, under the premise of ensuring a certain optical zone diameter, the ablation depth should be minimized to reduce the increase of the post-operative HOAs so as to improve the visual quality.

Keywords: High myopia, Laser refractive surgery, Visual acuity, Femtosecond LASIK, Triple-A procedure

\footnotetext{
*Correspondence: likai8922@163.com

${ }^{\dagger}$ Kai Li, Chuan-Wei Zhang and De-Jian Hong equally to this work (co-first author).

Department of Ophthalmology, Affiliated Hospital of Nanjing University of

Chinese Medicine,Nanjing, 155 Hanzhong Road, Nanjing 210029, Jiangsu,

China
}

(c) The Author(s). 2019 Open Access This article is distributed under the terms of the Creative Commons Attribution 4.0 International License (http://creativecommons.org/licenses/by/4.0/), which permits unrestricted use, distribution, and reproduction in any medium, provided you give appropriate credit to the original author(s) and the source, provide a link to the Creative Commons license, and indicate if changes were made. The Creative Commons Public Domain Dedication waiver (http://creativecommons.org/publicdomain/zero/1.0/) applies to the data made available in this article, unless otherwise stated. 


\section{Background}

Myopia is the most common refractive disorder. It is predicted that myopia and high myopia account for 49.8 and $9.8 \%$ of the world's population by 2050 respectively [1]. Patients with extreme myopia usually refer to those patients with SE exceeding - 9.00 D. To some extent, extreme myopia affects the patient's athletic ability, daily life and work. At present, surgery has become a better choice for high myopia correction. The current surgical procedures for high myopia include corneal refractive surgery and posterior phakic IOL surgery. Numerous studies have shown that both operations can achieve significant improvement in high myopia correction [2]. Laser in suit keratomileusis (LASIK) is a safe procedure with predictable results for high or low myopia correction, but the outcomes for extreme myopia is not satisfactory [3]. FS-LASIK has been developed rapidly for myopia correction with high accuracy and predictability in flap thickness creation [4]. It reduces the complications of flap making and makes ultra-thin corneal flap accurately, especially in the treatment of high myopia [5, 6]. However, whether the FS-LASIK surgery could achieve better results for extreme myopia is an important issue, especially in term of postoperative visual quality and iatrogenic keratectasia [7]. The Triple-A ablation profile (Carl Zeiss Meditec, Jena, Germany) combining minimal ablation depth and spherical aberration, guarantees excellent clinical outcomes for patients with high or low myopia [8-10]. Theoretically, the surgical procedure of combining femtosecond thin- flap and the Triple-A profile should be able to correct extreme myopia. Therefore, we conducted a prospective study to investigate the efficacy and safety of thin- flap FS-LASIK with the Triple-A profile for extreme myopia correction.

\section{Patients and methods}

In this prospective study, 90 eyes of 90 patients received FS-LASIK were enrolled at Affiliated Hospital of Nanjing University of Chinese Medicine, from January to July, 2016. Based on the SE, patients were divided into two groups: first group (ranged from $6.00 \mathrm{D}$ to $-9.00 \mathrm{D}$ ) and second group (ranged from 9.00D to $-11.15 \mathrm{D})$. This study was approved by the Ethics Committee of our institution and adhered to the tenets of the Declaration of Helsinki. An informed consent was obtained from each of the patients after explaining the nature of the study. The inclusion criteria included the study subjects over the age of 18 with stable refraction for at least two years, regular corneal topography, and no history of ocular surgery. Patients were required to follow up cotinuously for 6 months after surgery. All surgeries were performed by the same surgeon (LK).

\section{Data collection}

All patients underwent complete ophthalmic examinations, including the uncorrected distance visual acuity (UDVA), corrected distance visual acuity (CDVA), slitlamp microscopy, intraocular pressure measurement with non-contact tomometre (NCT), dilated indirect fundoscopy, and Pentacam Imaging examinations (Oculus, Wetzlar, Germany). Measurement of corneal higher-order aberrations (HOAs) and elevation of the posterior central elevation (PCE) were obtained using Pentacam in a dark room. The root mean square (RMS) of the 4th order spherical aberration, 3rd coma and total higher order aberrations were calculated. The $\triangle \mathrm{PCE}$ was defined the difference between the post-operative data and the pre-operative data. All patients have been followed for 6 months. Post-operative examinations were conducted at 1 day, 1 week, and 1 , 3 and 6 momths after surgery.

\section{Surgical procedure}

The Carl Zeiss Refractive Suite, specifically the Visumax femtosecond and MEL 90 excimer lasers (Carl Zeiss Meditec, Jena, Germany), was employed for all FS- LASIK procedures. All patients had planned flap with the $500-\mathrm{kHz}$ femtosecond laser. The flap parameters were as follows: $8.1 \mathrm{~mm}$ flaps diameters, 90 um flap thicknesss, $90^{\circ}$ side-cut angles, and $3.0 \mathrm{~mm}$ hinge length set in a superior orientation. After the flap was lifted, ablations were performed using the MEL-90 excimer laser with a tissue-saving function (triple-A profile). After surgery, the post-operative topical antibiotic was applied 4 times per day for 7 days and a topical steroid 4 times per day for 2 weeks, and a non-preservative tear supplement was prescribed for 1 month.

Table 1 Preoperative demographics of the study population (mean \pm SD and range)

\begin{tabular}{llll}
\hline Characteristics & Second group & First group & $P$ value \\
\hline No. of eyes & 43 & 47 & - \\
Age, y (range) & $24.3(17 \sim 40)$ & $22.5(17 \sim 39)$ & $0.163^{*}$ \\
Male/Female & $23 / 20$ & $23 / 24$ & $0.663 \dagger$ \\
Preoperative SE & $-9.50 \pm 0.58 \mathrm{D}$ & $-7.14 \pm 0.90 \mathrm{D}$ & $0^{*}$ \\
& $(-9.00 \sim-11.15 \mathrm{D})$ & $(-6.00 \sim-8.75 \mathrm{D})$ & \\
UDVA (LogMAR) & $1.544 \pm 0.237$ & $1.504 \pm 0.123$ & $0.336^{*}$ \\
& $(1.001 \sim 2.003)$ & $(1.302 \sim 1.701)$ & \\
CDVA (LogMAR) & $0.033 \pm 0.035$ & $0.015 \pm 0.039$ & $0.091^{*}$ \\
& $(-0.001 \sim 0.073)$ & $(-0.001 \sim 0.050)$ & \\
Corneal Thickness (um) & $548.8 \pm 18.1$ & $545.5 \pm 20.5$ & $0.098^{*}$ \\
& $(492 \sim 586)$ & $(492 \sim 583)$ & \\
\hline
\end{tabular}

UDVA: uncorrected distance visual acuity. CDVA: corrected distance visual acuity. D: diopters

* independent- sample $t$ test

tchi-square test 
Table 2 Comparison of the efficacy and safety index between second group and first group (mean \pm SD)

\begin{tabular}{lcll}
\hline Group & Eyes & Efficacy index & Safety index \\
\hline First group & 47 & $1.149 \pm 0.150$ & $1.135 \pm 0.154$ \\
Second group & 43 & $1.173 \pm 0.136$ & $1.158 \pm 0.137$ \\
$\mathrm{t}$ & & -1.317 & -1.291 \\
$P$ & & 0.188 & 0.197 \\
\hline
\end{tabular}

\section{Statistical analysis}

Date were analyzed using SPSS software (ver. 18; SPSS, Chicago, IL, United States) and presented as mean \pm standard deviation (SD). The normality of all data samples was performed using the Kolmogorov-Smirnov test. Independent-sample $\mathrm{t}$ test and chi-square test were used to compare the differences between baseline characteristics. The independent-sample $t$ test was used for comparisons between the first group and second group. The association between the ablation depth and the variation of
HOAs was evaluated using Pearson correlation coefficient. $P<0.05$ was considered as statistically significant difference.

\section{Results \\ Study population}

The pre-operative demographic data are listed in Table 1. No significant differences were observed in age, sex, pre-operative UDVA, CDVA, and central corneal thicknesses between the first and second groups except with pre-operative SE.

\section{Refractive outcomes}

Table 2 displayed the efficacy and safety index of 6 months after surgery, the index for the first group were $1.149 \pm 0.150$ and $1.135 \pm 0.154$, respectively, whereas the index for the second group were $1.173 \pm 0.136$ and $1.158 \pm 0.137$ respectively. There were no significant difference between the two groups $(P>0.05)$. Figure 1 shows the distribution of UDVA and CDVA after surgery

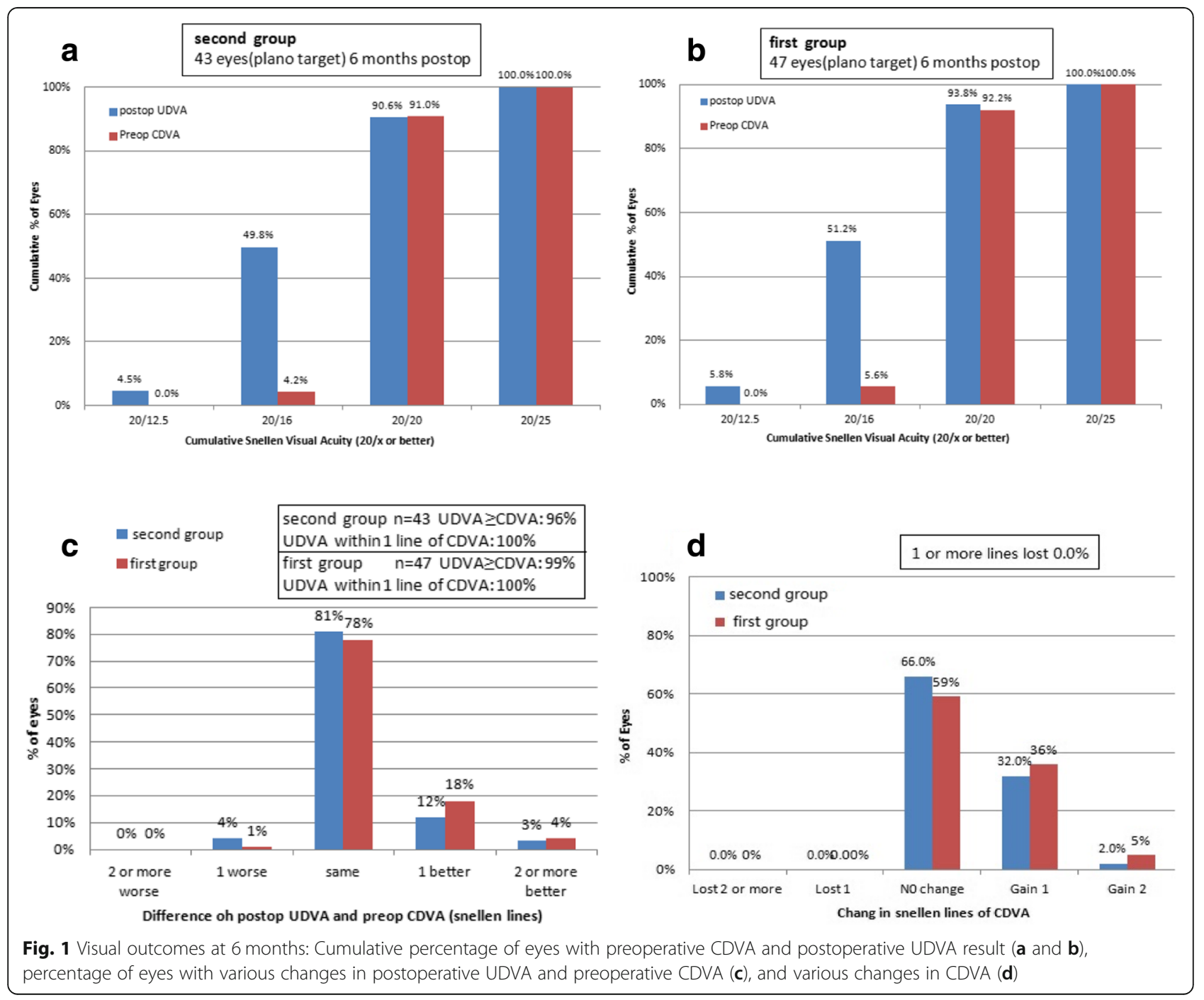


between the both groups. At sixth months after surgery, 90.6 and $49.8 \%$ of eyes in the second group had a UDVA of 20/20 and of 20/16, respectively (Fig. 1a). In the first group, 93.8 and $51.2 \%$ of the eyes had a UDVA of $20 / 20$ and of 20/16, respectively (Fig. 1b). There were no significant differences between the both groups at the 20/ 20 and the 20/16 levels $\left(\chi^{2}=0.264, P=0.607\right.$ and $\chi^{2}=$ $0.045, P=0.833$, respectively). The gain-loss data (pre-operative CDVA versus post-operative UDVA) showed that no eye lost more than one Snellen line of CDVA in either group (Fig. 1c). In contrast, $34 \%$ of the eyes in the second group and $41 \%$ of the eyes in the first group showed a gain of Snellen lines (Fig. 1d), but they showed no statistically significant difference between both groups $\left(\chi^{2}=0.599, P=0.439\right)$.

Figure $2 \mathrm{a}$ and $\mathrm{b}$ showed the scatter plots of the attempted versus the achieved SE correction at post-operative 6- month follow up. The percentage of the post-operative SE was shown in Fig. 2c that 82\% (35 eyes) and $100 \%$ (43 eyes) in the second group were within $\pm 0.50 \mathrm{D}$ and $\pm 1.00 \mathrm{D}$ of the attempted correction respectively, $84 \%$ (39 eyes) and 100\% (47 eyes) in the first group were within $\pm 0.50 \mathrm{D}$ and $\pm 1.00 \mathrm{D}$ respectively.

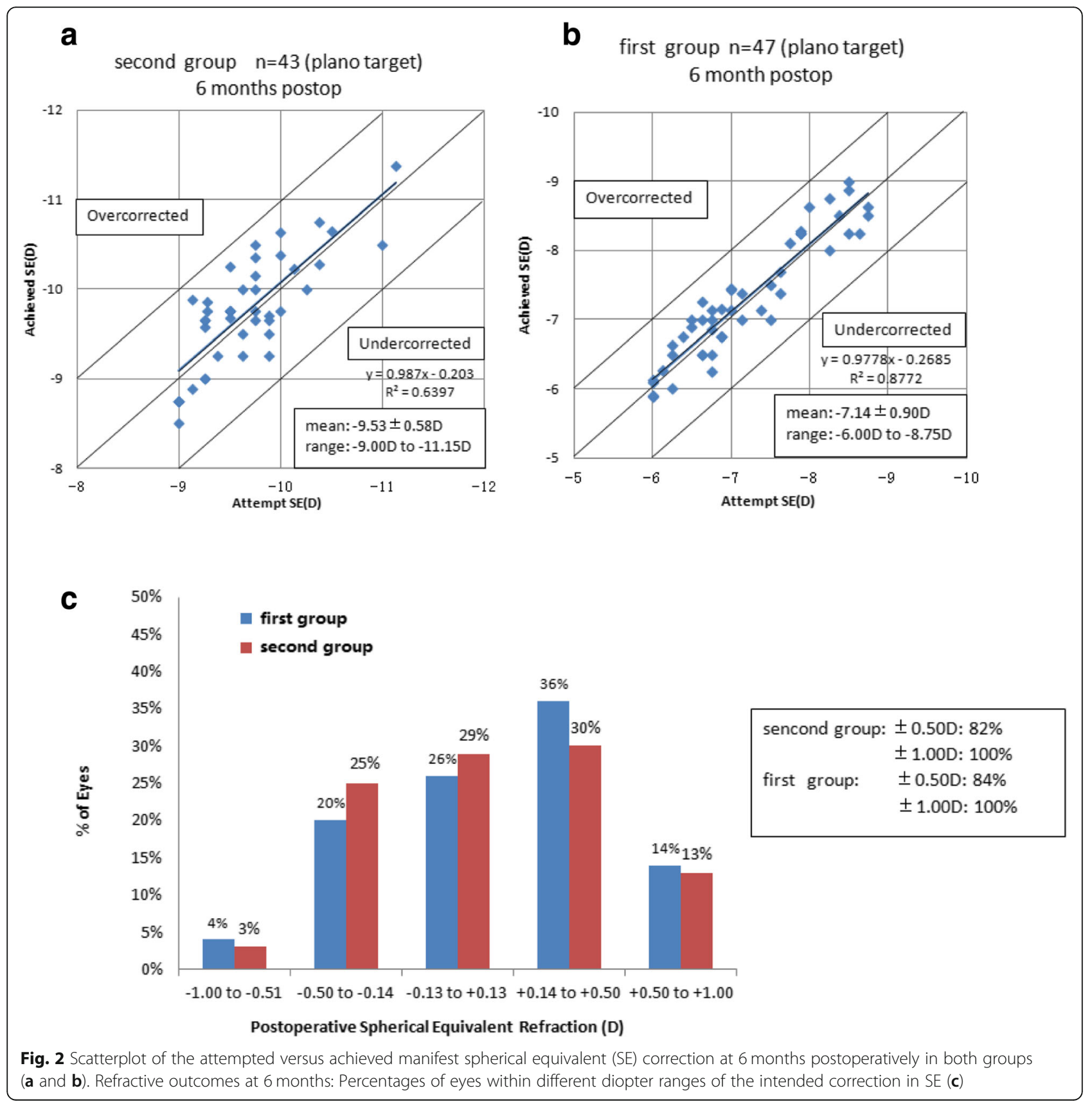




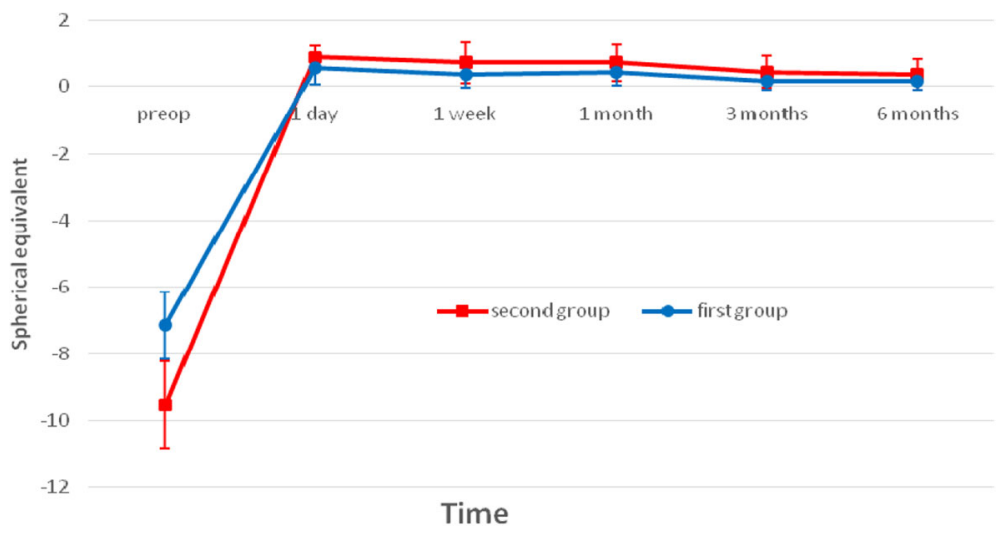

Fig. 3 Stability of spherical equivalent refraction

Figure 3 showed the trend of mean post-operative SE in both groups. At post-operatively 6-month follow up, the $\mathrm{SE}$ in the first and second groups were $0.15 \pm 0.26 \mathrm{D}$ and $0.36 \pm 0.46 \mathrm{D}$, respectively. There was no significant myopia regression in both groups after 6- month follow-up.

\section{Posterior central elevation (PCE) outcomes}

As shown in Fig. 4, the average PCE changes $(\triangle \mathrm{PCE})$ at 1,3 , and 6- month post-operative follow- up in the second group were $1.60 \pm 1.00 \mu \mathrm{m}, 1.68 \pm 1.22 \mu \mathrm{m}, 1.51 \pm$ $1.07 \mu \mathrm{m}$ respectively. The average $\triangle \mathrm{PCE}$ in the first group were $1.59 \pm 1.11 \mu \mathrm{m}, \quad 1.64 \pm 1.19 \mu \mathrm{m}, \quad 1.27 \pm$ $0.71 \mu \mathrm{m}$, respectively. One-way repeated measures ANOVA test showed no significant difference in PCE change over the 1, 3 and 6- month post-operative period for either the second group ( $\mathrm{F}=0.251, P=0.778)$ or the first group $(\mathrm{F}=1.705, P=0.186)$.

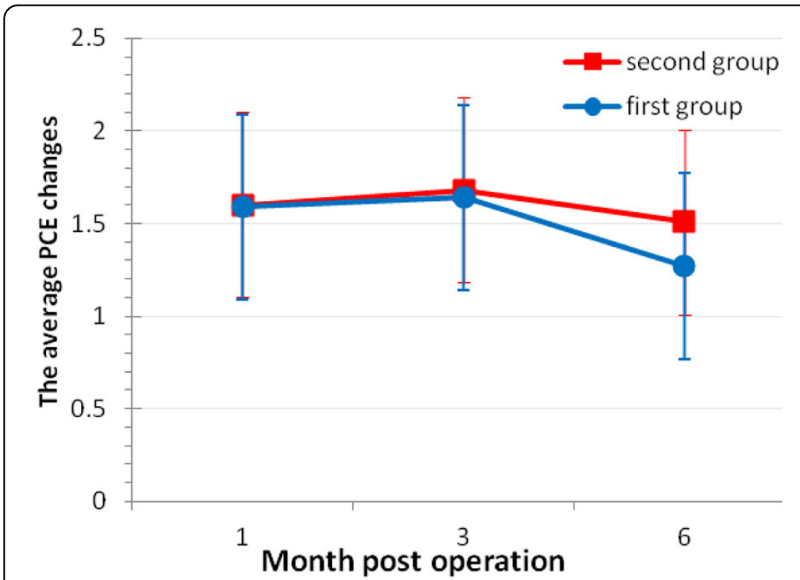

Fig. 4 Changes in posterior central elevation $(\triangle P C E)$ at 1 month, 3 months, 6 months post operation in two groups

\section{Corneal higher-order aberrations (HOA)}

Table 3 displayed that the values of HOA increased significantly in both groups after surgery. The induction of total HOAs, spherical aberration, and horizontal coma in the first group were significantly less than that in the second group at 6- month follow-up post-operatively ( $P$ $=0,0,0.019$ respectively), while the RMS value of vertical coma between both groups were no significantly difference $(P=0.927)$.

\section{Correlation between the ablation depth and the variation of HOA}

The tissue ablation was significantly correlated with the post-operative increases of total HOAs $(\mathrm{r}=0.426, P=$ $0.000)$, spherical aberration $(\mathrm{r}=0.243, P=0.021)$ and horizontal coma $(\mathrm{r}=0.341, P=0.001)$, but not with vertical coma $(\mathrm{r}=0.034, P=0.750)$.

\section{Discussion}

In recent years, corneal refractive surgery is a preferred method for myopia correction, but it is not optimal for patients with extreme myopia and thin corneal thickness. The post-operative visual acuity is easy to recede and the visual quality is usually affected after the surgery [11-13]. Lin et al. proposed the concept of thin flap LASIK and concluded that its combination with ultra-thin corneal flap cutting enables LASIK safely [14]. The thin-flap FS-LASIK not only increases the range of refractive correction, but also preserves the stromal bed thickness and increases the safety and stability of the surgery. The effect of FS- LASIK on low, medium and high myopia has been affirmed, but there are only few studies reporting the effect of extreme myopia [15-17]. MEL 90 excimer laser provides Triple-A ablation mode, which adopts the compensation algorithm of enhanced energy correction and integrates the cutting mode of aspherical and conserving corneal tissue. This new profile combines the Tissue Saving 
Table 3 Comparison of aberration before and after surgery between second group and first group (mean \pm SD)

\begin{tabular}{|c|c|c|c|c|c|c|c|c|c|}
\hline \multirow[t]{2}{*}{ Groups } & \multirow[t]{2}{*}{$n$} & \multicolumn{2}{|l|}{ Total HOAs } & \multicolumn{2}{|c|}{ Spherical aberration } & \multicolumn{2}{|c|}{ Horizontal coma } & \multicolumn{2}{|l|}{ Vertical coma } \\
\hline & & Pre-op & Post-6mo & Pre-op & Post-6mo & Pre-op & Post-6mo & Pre-op & Post-6mo \\
\hline First group & 47 & $0.344 \pm 0.088$ & $0.479 \pm 0.078$ & $0.204 \pm 0.071$ & $0.348 \pm 0.124$ & $0.205 \pm 0.119$ & $0.331 \pm 0.130$ & $0.043 \pm 0.026$ & $0.053 \pm 0.045$ \\
\hline Second group & 43 & $0.371 \pm 0.136$ & $0.604 \pm 0.103$ & $0.221 \pm 0.040$ & $0.437 \pm 0.100$ & $0.235 \pm 0.139$ & $0.409 \pm 0.182$ & $0.044 \pm 0.021$ & $0.054 \pm 0.022$ \\
\hline t & & 1.126 & 6.495 & 1.494 & 3.716 & 1.094 & 2.391 & 0.225 & 0.092 \\
\hline$p$ & & 0.264 & 0.000 & 0.140 & 0.000 & 0.277 & 0.019 & 0.822 & 0.927 \\
\hline
\end{tabular}

Ablation (TSA) profile with the Aberration Smart Ablation (ASA) profile, which better visual outcomes can be obtained in myopia correction, not only inducing less HOAs, but also reducing the ablation depth $[9,18]$. Reinstein et al. found that it achieved high safety and efficacy for sphere up to $-10.00 \mathrm{D}$ and cylinder up to $5.00 \mathrm{D}$ [10]. Therefore, it is feasible to correct extreme myopia with the surgical mode of combining the Triple-A profile of excimer laser and femtosecond thin-flap.

In the present study, we found that the UCVA of the two groups of patients has been significantly improved after surgery, indicating that the correction effect is ideal. The results of this study showed that the safety index and effectiveness index of each time point for the extreme myopia group were all $>1$ and no eyes demonstrated a loss in CDVA, indicating that FS-LASIK using the Triple-A profile has good safety and efficacy for high and extreme myopia correction. Another safety indicator for corneal refractive surgery is the change in the height of the PCE. Because the corneal integrity is destroyed after laser ablation, its biomechanical stability is lower than that before surgery, possibly leading to corneal posterior surface changes under intraocular pressure $[19,20]$. We investigated the potential change in corneal stability by analyzing PCE after surgery. The results showed that there was no significant change in the PCE after surgery in both groups, which further indicated that the safety of FS-LASIK with tissue saving mode for extreme myopia correction was similar to that for high myopia correction. In terms of post-operative stability, both groups had mild hyperopia drift after surgery, and it was more prominent in the second group during the early stage. The SE of both groups tended to be stable at 3- month post-operatively. The observation at 6- month follow-up showed that the FS-LASIK using the Triple-A profile had good refractive stability in extreme myopia subjects.

Corneal refractive surgery can help patients return to normal vision, while visual quality often declines, especially in the HOAs. After LASIK, there is often a problem of decline in visual quality, mainly due to the increase in HOAs caused by corneal flap and stromal ablation [21-23]. The increase of spherical aberration is mainly related to excimer ablation, while the increase of coma is related to the decentration of ablation [24]. Previous studies have shown that applying femtosecond laser to create a corneal flap produces less HOAs than the mechanical microkeratome $[25,26]$. In the present study, the induction of post-operative total HOA, spherical aberration and horizontal coma were significantly more obvious for eyes in extreme myopia group than for those in high myopia group, while there was no significant difference in vertical coma between the two groups. These results were in line with the correlation between the ablation depth and the variation of HOAs. With the increase of corneal tissue ablation depth, the amount of HOAs were increased after operation, showing a positive correlation pattern between them. The results indicated that the ablation depth should be minimized under the premise of ensuring a certain optical zone diameter, so as to reduce the increase of HOAs after operation.

\section{Conclusions}

In summary, the surgical mode of combining femtosecond thin-flap and the Triple-A profile of excimer laser showed comparable results in terms of efficacy, safety, and stability for extreme myopia (SE up to - 11.15D) and high myopia. However, for patients with high myopia, under the premise of ensuring a certain optical zone diameter, the ablation depth should be minimized to reduce the increase of post-operative HOAs. Further studies with larger cohort sizes and longer-term of follow-up should be required to corroborate these findings.

\section{Abbreviations \\ CCT: Central corneal thickness; CDVA: Corrected distance visual acuity; FS- LASIK: Femtosecond laser-assisted LASIK; HOAs: High-order aberrations; RMS: root mean square; LASIK: Laser-assisted in situ keratomileusis; logMAR: Logarithm of minimum angle resolution; SE: Spherical equivalent; UDVA: Uncorrected distance visual acuity}

\section{Acknowledgements}

We are grateful to the myopia subjects in this study. The authors would like to thanks Prof. Tsz Kin Ng from Joint Shantou International Eye Center of Shantou University and the Chinese University of Hong Kong for the language editing and manuscript revision. 


\section{Funding}

This study was funded by Six Talent Peaks Project in Jiangsu Province (grant no. WSW-048) .

\section{Availability of data and materials}

The data of the current study are available from the corresponding author on reasonable request.

\section{Authors' contributions}

LK conceived of the study and drafted the manuscript. ZCW collected the data and revised the manuscript. HDJ collected the data and involved in drafting the manuscript. LK performed the statistical analysis. WJ and YYS participated in the design of the study and critically revised the manuscript. All authors read and approved the final manuscript.

\section{Ethics approval and consent to participate}

This study followed the tenets of the Declaration of Helsinki and was approved by the ethics committee of the Affiliated Hospital, Nanjing University of Chinese Medicine. Informed written consent was obtained from all participants.

\section{Consent for publication}

Not applicable.

\section{Competing interests}

The authors declare that they have no competing interests.

\section{Publisher's Note}

Springer Nature remains neutral with regard to jurisdictional claims in published maps and institutional affiliations.

Received: 26 September 2018 Accepted: 25 April 2019 Published online: 10 May 2019

\section{References}

1. Holden BA, Fricke TR, Wilson DA, Jong M, Naidoo KS, Sankaridurg P, Wong TY, Naduvilath TJ, Resnikoff S. Global prevalence of myopia and high myopia and temporal trends from 2000 through 2050. Ophthalmology. 2016;123(5):1036-42.

2. Ali M, Kamiya K, Shimizu K, Igarashi A, Ishii R. Clinical evaluation of corneal biomechanical parameters after posterior chamber phakic intraocular lens implantation. Cornea. 2014;33(5):470-4.

3. Alió JL, Soria F, Abbouda A, Peña-García P. Laser in situ keratomileusis for6.00 to- 18.00 diopters of myopia and up to- 5.00 diopters of astigmatism: 15-year follow-up. J Cataract Refract Surg. 2015;41(1):33-40.

4. Kanellopoulos AJ, Asimellis G. LASIK ablation centration: an objective digitized assessment and comparison between two generations of an excimer laser. J Refract Surg. 2015;31(3):164-9.

5. McLaren JW, Bourne WM, Maguire LJ, Patel SV. Changes in keratocyte density and visual function five years after laser in situ keratomileusis: femtosecond laser versus mechanical microkeratome. Am J Ophthalmol. 2015;160(1):163-70.

6. Soong HK, Malta JB. Femtosecond lasers in ophthalmology. Am J Ophthalmol. 2009;147(2):189-97 e182

7. Bühren J, Kook D, Yoon G, Kohnen T. Detection of subclinical keratoconus by using corneal anterior and posterior surface aberrations and thickness spatial profiles. Invest Ophthalmol Vis Sci. 2010;51(7):3424-32.

8. Dausch D, Dausch B, Wottke M, van Langeweyde GS. Comparison of clinical outcomes in PRK with a standard and aspherical optimized profile: a full case analysis of 100 eyes with 1-year follow-up. Clin Ophthalmol. 2014;8:2251.

9. Chen Y, Yang D, Han T, Xu H, Li M, Zhou X. A pilot study: LASEK with the triple-a profile of a MEL 90 for mild and moderate myopia. BMC Ophthalmol. 2017;17(1):98.

10. Meyer B, van Langeweyde GS, Wottke M. Refractive outcomes of an advanced aspherically optimized profile for myopia corrections by LASIK: a retrospective comparison with the standard aspherically optimized profile. Clin Ophthalmol. 2015;9:379.

11. Reinstein DZ, Carp GI, Lewis TA, Archer TJ, Gobbe M. Outcomes for myopic LASIK with the MEL 90 excimer laser. J Refract Surg. 2015;31(5):316-21.
12. Khachikian SS, Belin MW. Bilateral corneal ectasia after laser in situ keratomileusis. J Cataract Refract Surg. 2010;36(11):2015.

13. Moshirfar M, Gardiner JP, Schliesser JA, Espandar L, Feiz V, Mifflin MD, Chang JC. Laser in situ keratomileusis flap complications using mechanical microkeratome versus femtosecond laser: retrospective comparison. $J$ Cataract Refract Surg. 2010;36(11):1925-33.

14. Lin RT, Lu S, Wang LL, Kim ES, Bradley J. Safety of laser in situ keratomileusis performed under ultra-thin corneal flaps. J Refract Surg. 2003;19(2):S231-6.

15. Kim JY, Kim MJ, H-j C, Pak JH, Tchah H. A femtosecond laser creates a stronger flap than a mechanical microkeratome. Invest Ophthalmol Vis Sci. 2006:47(2):599-604.

16. Calvo R, McLaren JW, Hodge DO, Bourne WM, Patel SV. Corneal aberrations and visual acuity after laser in situ keratomileusis: femtosecond laser versus mechanical microkeratome. Am J Ophthalmol. 2010;149(5):785-93.

17. Lim $\mathrm{T}$, Yang $\mathrm{S}$, Kim $\mathrm{M}$, Tchah $\mathrm{H}$. Comparison of the IntraLase femtosecond laser and mechanical microkeratome for laser in situ keratomileusis. Am J Ophthalmol. 2006;141(5):833-9.

18. Dubbelman M, Sicam V, Van der Heijde G. The shape of the anterior and posterior surface of the aging human cornea. Vis Res. 2006;46(6-7):993-1001.

19. Lee MJ, Lee SM, Lee HJ, Wee WR, Lee JH, Kim MK. The changes of posterior corneal surface and high-order aberrations after refractive surgery in moderate myopia. Korean J Ophthalmol. 2007;21(3):131-6.

20. Porter J, MacRae S, Yoon G, Roberts C, Cox IG, Williams DR. Separate effects of the microkeratome incision and laser ablation on the eye's wave aberration. Am J Ophthalmol. 2003;136(2):327-37.

21. Durrie DS, Kezirian GM. Femtosecond laser versus mechanical keratome flaps in wavefront-guided laser in situ keratomileusis: prospective contralateral eye study. J Cataract Refract Surg. 2005;31(1):120-6.

22. Tran DB, Sarayba MA, Bor Z, Garufis C, Duh Y-J, Soltes CR, Juhasz T, Kurtz RM. Randomized prospective clinical study comparing induced aberrations with IntraLase and Hansatome flap creation in fellow eyes: potential impact on wavefront-guided laser in situ keratomileusis. J Cataract Refract Surg. 2005;31(1):97-105

23. Mok KH, hong Lee WW. Effect of optical zone ablation diameter on LASIKinduced higher order optical aberrations. J Refract Surg. 2005;21 (2):141-3.

24. Kim A, Chuck RS. Wavefront-guided customized corneal ablation. Curr Opin Ophthalmol. 2008;19(4):314-20.

25. Agarwal S, Thornell E, Hodge C, Sutton G, Hughes P. Visual outcomes and higher order aberrations following LASIK on eyes with low myopia and astigmatism. Open Ophthalmol J. 2018;12(1):84-93.

26. Torky MA, Al Zafiri YA, Khattab AM, Farag RK, Awad EA. Visumax femtolasik versus Moria M2 microkeratome in mild to moderate myopia: efficacy, safety, predictability, aberrometric changes and flap thickness predictability. BMC Ophthalmol. 2017;17(1):125

Ready to submit your research? Choose BMC and benefit from:

- fast, convenient online submission

- thorough peer review by experienced researchers in your field

- rapid publication on acceptance

- support for research data, including large and complex data types

- gold Open Access which fosters wider collaboration and increased citations

- maximum visibility for your research: over $100 \mathrm{M}$ website views per year

At $\mathrm{BMC}$, research is always in progress.

Learn more biomedcentral.com/submissions 